\title{
Research of Hydraulic Drive Control System in Hydraulic Elevator Based on P-Q Valve
}

\author{
Zhong LIU1,a, Zhanwei GAO ${ }^{2, b}$, Neng YANG ${ }^{2}$, Yuanming HUO², Junjun LIU \\ ${ }^{1}$ Changshu Institute of Technology, School of Mechanical Engineering, Changshu, 215500, China \\ 2 Soochow University, School of Mechanical Engineering, Suzhou, 215502, China \\ aemail: liuzhong678@sina.com, bemail:g514612@163.com
}

Keywords: P-Q valve; hydraulic elevator; hydraulic driving control system; Simulation

\begin{abstract}
Electro hydraulic proportional pressure-flow compound valve ( $\mathrm{P}-\mathrm{Q}$ valve) is a new type of energy saving combination valve. The velocity and output force of the actuator can be proportionally controlled by the P-Q valve in different working state. The author puts forward a new scheme that the hydraulic elevator applies the P-Q valve to hydraulic driving control system. The author also makes theoretic analysis and builds a model of the elevator mechanical drive system and hydraulic driving system, according to which the system is simulated by computer. The results show that: the hydraulic driving control system which is based on P-Q valve of the hydraulic elevator has the advantage of smooth starting, high control precision and small impact in the case of emergency stop.
\end{abstract}

\section{Introduction}

With the rapid development of our economy and the improvement of people's living quality, the demand of people for elevator is becoming stronger and stronger. As an important kind of elevator, hydraulic elevator with its high load, good stability and other unique advantages is widely used. Hydraulic elevator has throttle and volume velocity control principles. Although the throttle control system installed with high power and high energy consumption, the technology is mature, each element has the advantages of simple manufacture, low cost and the system is easy to control, so it is more widely used than others. Therefore, to improve the hydraulic system of the hydraulic elevator on the premise of the throttle speed control with low cost has very important practical significance to reduce the installed power and energy consumption and improve its stability [1].

Electro hydraulic proportional pressure-flow compound valve (P-Q valve) is a new type of energy-saving combination valve. The velocity and output force of the actuator can be proportionally controlled by the P-Q valve in different working state [2]. Therefore, The author puts forward a new scheme that the hydraulic elevator applies the P-Q valve to hydraulic driving control system, trying to reduce the installed power and energy consumption, improve the operation stability and other aspects to make beneficial attempt.

\section{The principle of the elevator driving control system ${ }^{[3]}$ [4]}

The whole scheme of electro-hydraulic proportional drive control system of the new type hydraulic elevator is shown in Fig.1. Elevator system is composed of mechanical drive and hydraulic drive. 


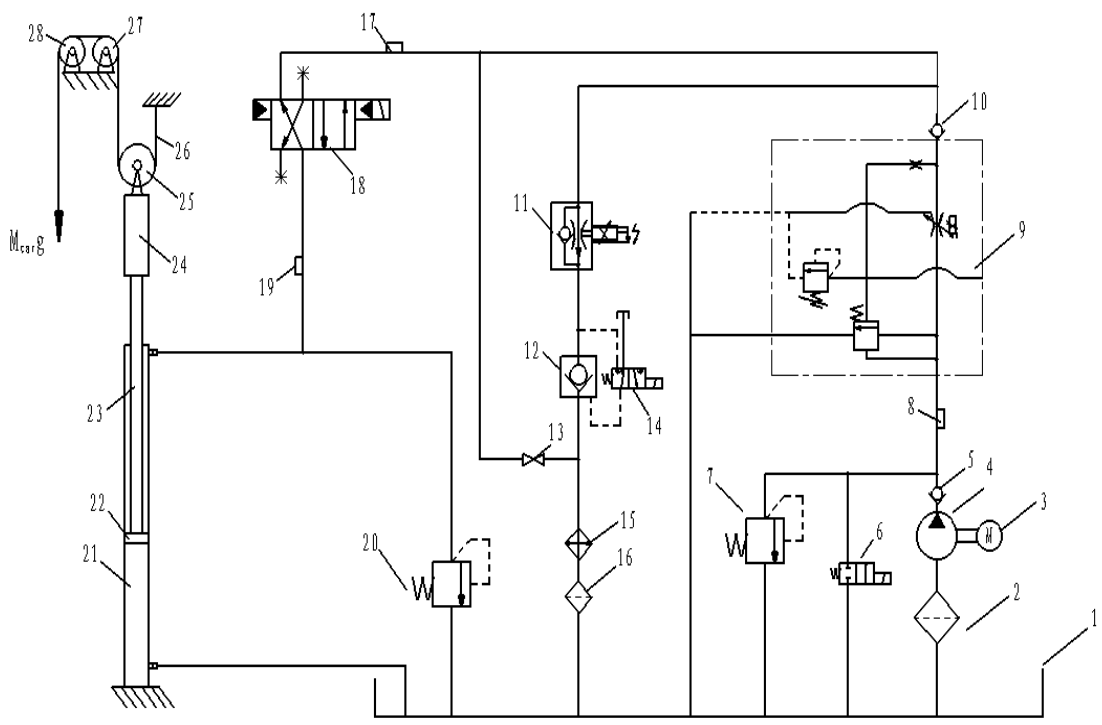

1. Tank 2.Filter 3.Motor 4.Vane Pump 5.Check Valve 6.Electromagnetic Valve 7.Relief Valve 8. Pressure Sensor 9.Proportional pressure and flow compound valve 10.Check Valve 11.Proportional speed regulating valve 12.Fluid control one-way valve 13. Manual cut-off valve 14.Solenoid ball valve 15.Radiator 16.Filter 17. Pressure Sensor 18.solenoid directional control valve 19.Pressure Sensor 20.Relief Valve 21.Piston cylinder 22.Piston 23.Piston rod 24.Balance weight 25.Movable pulley 26.wirerope 27. Guide pulley 28.traction sheave

Fig.1 Schematic diagram of the hydraulic elevator

The piston rod of the hydraulic cylinder is connected with a balance-weight, wire rope bypasses the pullet block and the car is pulled by the piston rod to realize the elevator upward. Using the electro-hydraulic proportional pressure-flow compound valve as the main control valve to control the size of the flow into the piston cylinder so as to realize the stable control of the elevator speed. Depending on the weight of the car to achieve the elevator car run down and this time the pump in the low-pressure unloading state.

Compared with the tradition hydraulic system of the hydraulic elevator, the drive control system has the following advantages: (1) Due to the adoption of the counterweight, the system can greatly reduce the installed power and has good energy saving effect. (2) The hydraulic system adopts proportional pressure-flow valve so that the control precision of the system is high and the elevator has good stability and comfort. (3) The proportional pressure-flow valve of the hydraulic system is composed of proportional flow control valve and a parallel constant difference overflow valve, and the valve with load sensitive function, can make that the pump outlet pressure is always higher than the load pressure of $0.6-0.9 \mathrm{MPa}$ to achieve the effect of saving energy. (4) Because the system uses a new type combination valve so hydraulic elevator can achieve a smooth start and prevent too big impact of the car when the elevator in emergency stop, at the same time, it can realize no-load start function and has a good effect on protecting the motor and prolonging the service life of the motor.

\section{Electro-hydraulic compound drive system modeling}

Hydraulic elevator car is dragged by wire rope, wire rope through the pulley block is connected with the top of the balance-weight frame and the bottom of the balance-weight frame is mounted directly on the top of piston rod. Therefore, the system mainly includes the following models: piston cylinder-wire rope pulley block-car model and P-Q valve- piston cylinder model.

\section{1 piston cylinder + steel wire rope pulley block + car model}

In the actual design of hydraulic elevator system, considering the characteristics of high security usually chooses the wire rope with larger rigidity. The studied system of this article uses 4 wire ropes. Because the wire rope stiffness is far greater than the hydraulic cylinder system stiffness, for the convenience of analysis, only the hydraulic cylinder system stiffness is considered as the main 
factor affecting the motion characteristics of the car ${ }^{[5]}$.

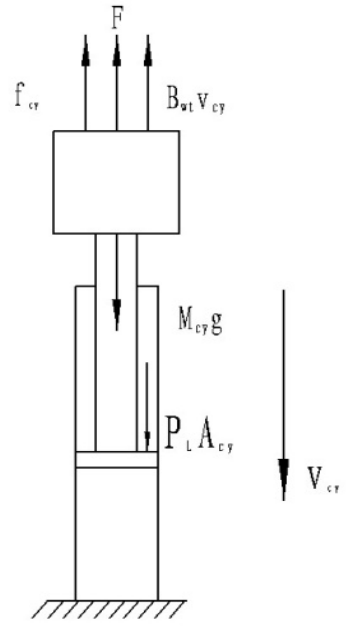

Fig. 2 Mechanics analysis of piston cylinder and balance-weight

The piston rod of the hydraulic cylinder connects counterweight by bolts in this system, so they are considered as a whole. The force diagram shown in Fig. 2, the kinetics equation is:

$$
M_{c y} \frac{d v_{c y}}{d t}=P_{L} A_{c y}+M_{c y} g-f_{c y}-B_{w t} v_{c y}-F_{L}
$$

In the formula: $M_{c y}$-total mass of the piston rod and the counterweight $(\mathrm{kg}) ; V_{c y}$ - velocity of piston $\operatorname{rod}(\mathrm{m} / \mathrm{s})$; t-time $(\mathrm{s}) ; \mathrm{P}_{\mathrm{L}}$-piston cylinder rod chamber pressure $(\mathrm{Pa}) ; A_{c y}$-piston pressure area $\left(\mathrm{m}^{2}\right) ; F_{L}$-load force of the car $(\mathrm{N}) ;$ g-gravitational acceleration $\left(\mathrm{m} / \mathrm{s}^{2}\right) ; f_{c y}$-dynamic friction force of the piston rod moves $(\mathrm{N}) ; B_{w t}$-coefficient of viscosity of hydraulic oil $(\mathrm{N} \cdot \mathrm{m} / \mathrm{s})$.

For the car, the kinetics equation is:

$$
2 M_{c a r} \frac{d v_{c y}}{d t}=F_{c a r}-f_{c a r}-M_{c a r} g
$$

In the formula: $M_{c a r}$-quality of the car $(\mathrm{kg}) ; V_{c y}$-velocity of piston $\operatorname{rod}(\mathrm{m} / \mathrm{s}) ; F_{c a r}$-pull of wire rope on the car $(\mathrm{N}) ; f_{c a r}$-friction between the car and the rail $(\mathrm{N})$.

\subsection{P-Q valve + hydraulic cylinder model}

Considering the compressibility of hydraulic oil, the relationship between the piston cylinder speed and flow into the hydraulic cylinder for:

$$
v_{c y}=\left(Q-\frac{V}{E_{\beta}} \cdot \frac{d P}{d t}\right) \cdot \frac{1}{A_{c y}}
$$

Therefore:

$$
\frac{d P}{d t}=\frac{E_{\beta}}{V}\left(Q-v_{c y} \cdot A_{c y}\right)
$$

In the formula: P-hydraulic cylinder cavity pressure (Pa); t-time(s); $\mathrm{E}_{\beta}$ - fluid bulk modulus of elasticity $(\mathrm{Pa})$; V-oil volume between the valve and the hydraulic cylinder $\left(\mathrm{m}^{3}\right)$; Q-flow into hydraulic cylinder $\left(\mathrm{m}^{3} / \mathrm{s}\right) ; V_{c y}$-velocity of piston $\operatorname{rod}(\mathrm{m} / \mathrm{s}) ; A_{c y}$ - piston pressure area $\left(\mathrm{m}^{2}\right)$.In the formula, cavity $(\mathrm{V})$ is consisted by two parts: the volume $\left(\mathrm{V}_{0}\right)$ of the basic fixed pipe cavity and the cavity volume changing with the displacement of the piston rod. Therefore, $V=V_{0}+A_{c y} \int_{0}^{t} v_{c y} d t, \mathrm{~V}$ will be substituted into the formula: 


$$
v_{c y}=\left(Q-\frac{V_{0}+A_{c y} \cdot \int_{0}^{t} v_{c y} d t}{E_{\beta}} \cdot \frac{d P}{d t}\right) \cdot \frac{1}{A_{c y}}
$$

Flow into the hydraulic cylinder is controlled by the P-Q valve:

$$
Q=q_{v}=C_{d} A(x) \sqrt{2 \Delta p / \rho}
$$

In the formula: $\mathrm{C}_{\mathrm{d}}$-flow coefficient; $\mathrm{A}(\mathrm{x})$-valve opening area; $\rho$-fluid density; $\triangle \mathrm{p}$-pressure difference between inlet and outlet of the throttle orifice.

The transfer function of two order system of spool displacement $\mathrm{X}(\mathrm{s})$ and electric current $\mathrm{I}(\mathrm{s})$ for $\mathrm{P}-\mathrm{Q}$ valve is:

$$
\frac{X(s)}{I(s)}=\frac{K_{i}}{s^{2}+\frac{B}{M} s+\frac{K_{s}+K_{y}}{M}}
$$

In the formula: $\mathrm{K}_{\mathrm{i}}$-electromagnetic force coefficient of the proportional electromagnet; $K_{s}$-spring stiffness of the armature yoke; $K_{y}$-spring force of the valve at the initial position; B-damping coefficient; M-quality of the armature yoke ${ }^{[6]}$.

\section{Simulation analysis}

The simulation model and the selected parameters of the component based on the system scheme is established in the hydraulic simulation platform of AMESim, as shown in Figure.3 Setting the simulation parameter of the system: the pressure of the hydraulic system is $5 \mathrm{MPa}$, the maximum flow is $72.1 \mathrm{~L} / \mathrm{min}$ and the load is $1450 \mathrm{~kg}{ }^{[7][8]}$.

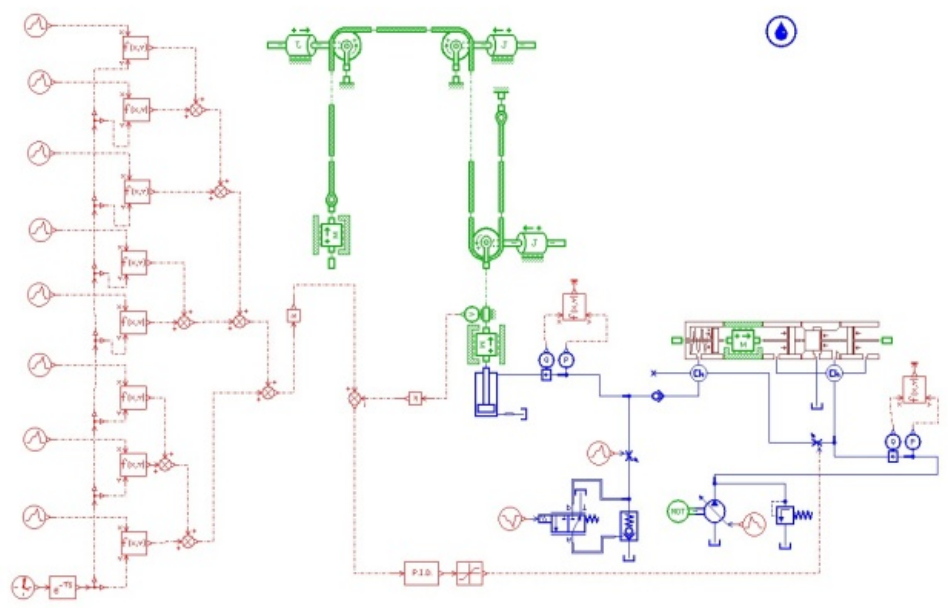

Fig.3.The system simulation model of the elevator

\subsection{Simulation analysis of the elevator speed}

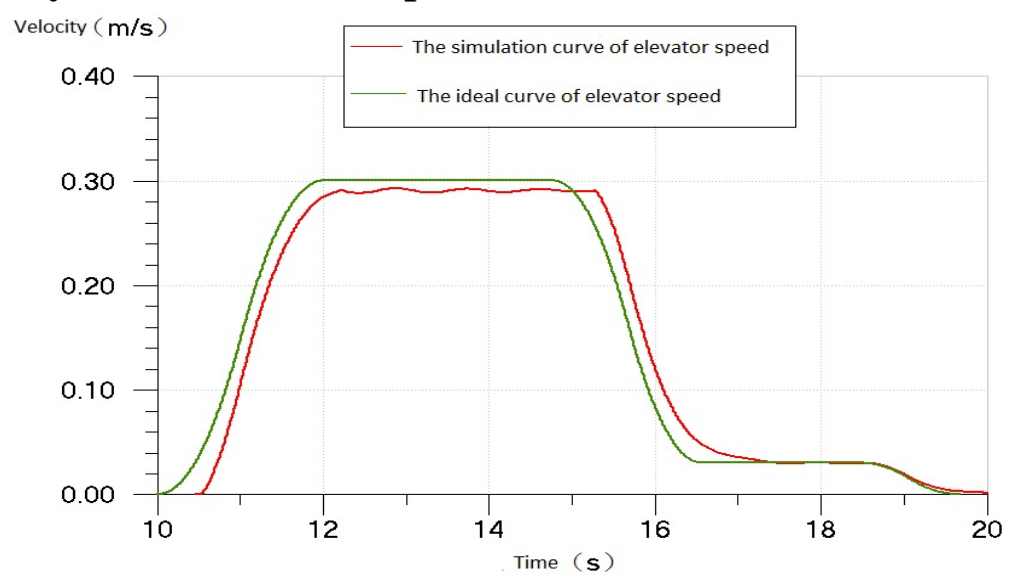

Fig.4 The simulation speed curve and ideal velocity curve 


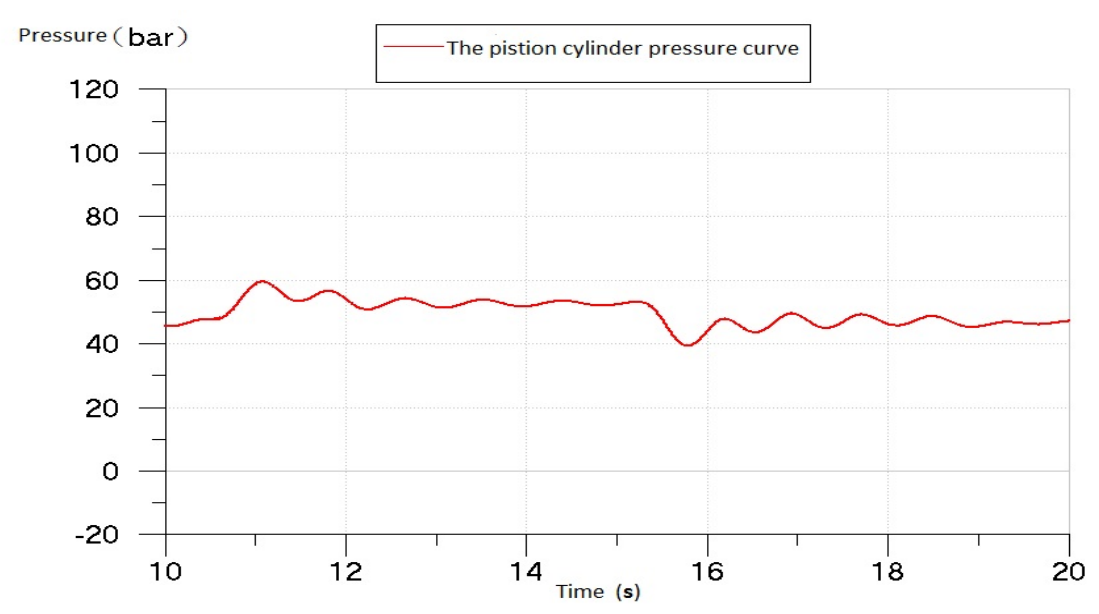

Fig.5 Pressure curve of the piston cylinder inlet

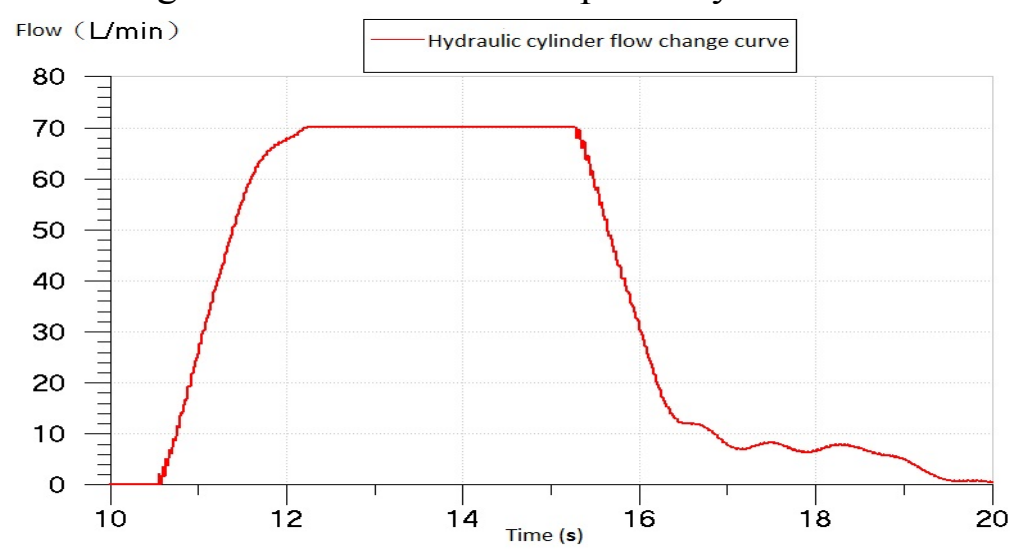

Fig.6 Flow curve of the piston cylinder inlet

According to the simulation curve in Figure 4, the car speed simulation curve of the scheme and the ideal speed curve are basically consistent, the simulation curve start gently and has smaller error compared with ideal speed curve. After calculation, the scheme meets the design requirements. Through the simulation curves in Figure 5 and Figure 6, the average pressure of piston cylinder cavity is $4.89 \mathrm{MPa}$, the change tendency of flow curve and the velocity curve of the car are similarly and the maximum flow $(72.1 \mathrm{~L} / \mathrm{min})$ is the same as the theory value. The simulation results show that the P-Q valve controls the pressure and flow of the hydraulic system is good and this scheme is designed reasonable, the car running can meet the design performance of requirement.

\subsection{Simulation analysis of the impact in emergency stop}

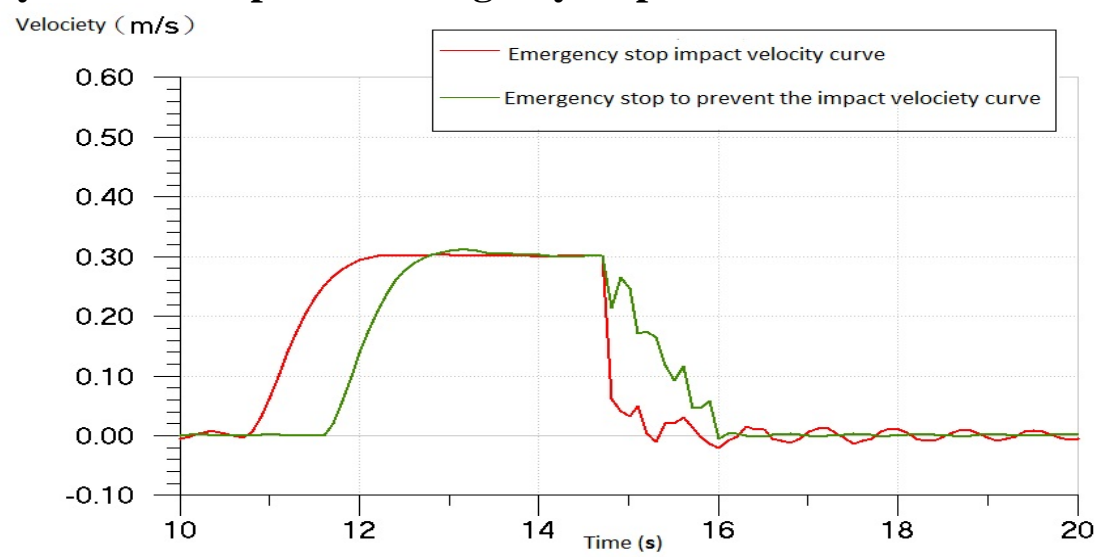

Fig.7 The effect of the relief valve for the speed of the car in emergency stop 


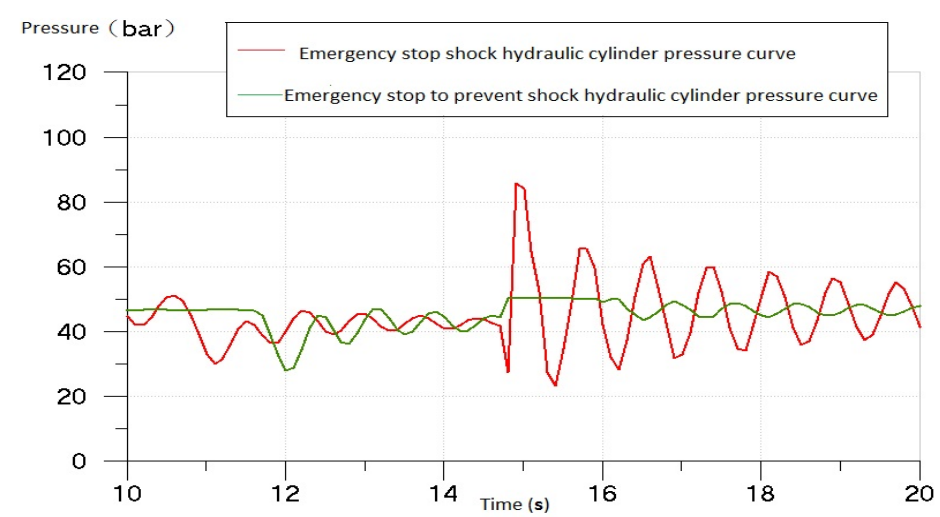

Fig.8 The effect of the relief valve for the pressure of the cylinder in emergency stop

Special conditions, elevator emergency stop will greatly influence the elevator comfort even security. In the scheme a relief valve is installed on the oil outlet of the hydraulic cylinder to reduce the sudden stop shock to the system. By the simulation curve can be seen that set the pressure value of the relief valve reasonable can effectively limit the outlet pressure of the hydraulic cylinder and make the car speed slow down in emergency stop to play a good role of preventing sudden stop shock.

\section{Conclusion}

Put forward a new kind of scheme and apply P-Q valve in the drive control system of the hydraulic elevator. Based on the driving system of theoretical analysis, mathematical modeling and simulation analysis, the results show that: this system can realize smooth starting of the hydraulic elevator and prevent sudden stop shock, has a certain reference value and practical significance for the drive system research of the hydraulic elevator.

\section{References}

[1] Deng Zhi-xian, Li Jing. Design and analysis of a new type of valve controlled hydraulic elevator system [J].Hydraulics Pneumatics and Seals, 2003(5):9-11.

[2] Huang Zhi-jian. Hydraulic servo and proportional control technology [M]. China Electric Power Press, 2012:128-131.

[3] Wu, D.; Burton, R.; Schoenau. Analysis of a pressure-compensated flow control valve [J]. Journal of dynamic systems measurement and control-transactions of the ASME, 2007,129 (2):98-103.

[4] Bahr, Khailil Medhat K; Loper Donald, M. Hydraulic system protection against catastrophic line failure using newly developed safety valve [J]. Fluid Power, 2008(9):41-46.

[5] Ying Xiu-hua. Research the single chip microcomputer speed control system of hydraulic elevator [D].Zhejiang University, 2002.

[6] Li Xiao-bo. Research the speed control system of hydraulic elevator based on the proportion of new electro hydraulic integrated valve [D]. Zhejiang University, 2002.

[7] Yang Hui-xian, Cai Yan-ping, Yang Xin-li. The speed control of hydraulic elevator based on genetic tuning PID [J].Control Engineering of China, 2012, 19(2):203-205.

[8] Lu Hong-ying, Jiang Ji-hai, Wang Di. Study on Hydraulic Transformer Driving Linear Load System Based on Fuzzy Tuning PID Control Strategy [J].Machine Tool and Hydraulic, 2009, 37(1):57-61. 